\title{
Role of endocannabinoid CB1 receptors in Streptozotocin-induced uninephrectomised Wistar rats in diabetic nephropathy
}

\author{
Jayarami Reddy Medapati ${ }^{1}$, Deepthi Rapaka', Veera Raghavulu Bitra ${ }^{1 *}$ D, Santhosh Kumar Ranajit ${ }^{2}$, \\ Girija Sankar Guntuku ${ }^{1}$ and Annapurna Akula ${ }^{1}$
}

\begin{abstract}
Background: The endocannabinoid CB1 receptor is known to have protective effects in kidney disease. The aim of the present study is to evaluate the potential agonistic and antagonistic actions and to determine the renoprotective potential of CB1 receptors in diabetic nephropathy. The present work investigates the possible role of CB1 receptors in the pathogenesis of diabetes-induced nephropathy. Streptozotocin (STZ) $(55 \mathrm{mg} / \mathrm{kg}$, i.p., once) is administered to uninephrectomised rats for induction of experimental diabetes mellitus. The CB1 agonist (oleamide) and CB1 antagonist (AM6545) treatment were initiated in diabetic rats after 1 week of STZ administration and were given for 24 weeks.

Results: The progress in diabetic nephropathy is estimated biochemically by measuring serum creatinine $(1.28 \pm 0.03)(p<$ $0.005)$, blood urea nitrogen $(67.6 \pm 2.10)(p<0.001)$, urinary microprotein $(74.62 \pm 3.47)(p<0.005)$ and urinary albuminuria $(28.31 \pm 1.17)(p<0.0001)$. Renal inflammation was assessed by estimating serum levels of tumor necrosis factor alpha (75.69 \pm 1.51$)(p<0.001)$ and transforming growth factor beta $(8.73 \pm 0.31)(p<0.001)$. Renal morphological changes were assessed by estimating renal hypertrophy $(7.38 \pm 0.26)(p<0.005)$ and renal collagen content $(10.42 \pm 0.48)(p<0.001)$.

Conclusions: From the above findings, it can be said that diabetes-induced nephropathy may be associated with overexpression of $\mathrm{CB} 1$ receptors and blockade of $\mathrm{CB} 1$ receptors might be beneficial in ameliorating the diabetes-induced nephropathy.
\end{abstract}

Keywords: Diabetic nephropathy, Albuminuria, Uninephrectomy, Oleamide

\section{Background}

Diabetic nephropathy $(\mathrm{DN})$ is classically a multistage clinical syndrome characterised by the progressive and persistent rise in urinary albumin elimination with a constant rise in blood pressure, decline in glomerular filtration rate (GFR) and enhanced fluid retention, resulting in renal dysfunction and end-stage renal disease [1]. Chronic hyperglycemia results in pathological variations in the anatomy and functions of the kidney [2, 3]. The structural abnormalities comprise arteriolar hyalinisation, glomerular hypertrophy, glomerular basement

\footnotetext{
*Correspondence: raghavab27@gmail.com

'A U College of Pharmaceutical Sciences, Andhra University, Visakhapatnam, Andhra Pradesh 530003, India

Full list of author information is available at the end of the article
}

membrane thickening, and mesangial and interstitial enlargement. Renal functional aberrations include a decrease in GFR, microalbuminuria and an increase in kidney size [4].

Due to the complexity of primary signalling culprits involved in the DN disease pathogenesis, very few therapeutic choices are presently available.

Compelling evidence from the last two decades indicates that the endocannabinoid system (ECS) influences and triggers diabetic microvascular complications [5]. ECS is a lipid signalling arrangement comprises of cannabinoid receptors along with lipid ligands and machinery of enzymes [6]. Endocannabinoids are the products of arachidonic acid, resembling supplementary fat 
transmitters (eicosanoids like prostaglandins or leukotrienes) [7].

Emerging data suggest that ECS contributes to the loss of $\beta$ cells and triggers diabetes via the inflammatory and cell death process. The pancreatic $\beta$ cells express the $\mathrm{CB} 1$ receptors, and their activation stimulates the release of insulin [8].

Cannabinoid receptors are receptors connected to Gprotein and are abundantly expressed in the central nervous system and organs associated with the immune system. CB1 cannabinoid receptors are principally expressed in the CNS and peripherally in tissues involved in energy homeostases, such as the liver, adipose, pancreatic, and skeletal muscle. Experimental evidence [9] and clinical studies [10] had revealed that CB1 receptors are expressed within glomeruli at low levels. Furthermore, in diseases such as obesity and diabetes, higher levels of endocannabinoids have been recognized [11].

The CB1 receptors are over-expressed within the kidney during pathological environments [12], resulting in the over-expression of the functional potential of the kidney. The crucial role of inflammation and the manifestation of inflammatory mediators such as chemokines, cytokines and molecules of cell adhesion in kidney tissues has been highlighted by mounting evidence in the current decade [11]. Kidney damage in DN can therefore be attenuated by strategies aimed at reducing microinflammation through CB1 receptors.

Oleamide is an amide of oleic acid, a fatty acid. Architecturally, oleamide is related to the endogenous cannabinoid anandamide and has the potential to be coupled as a complete agonist with the CB1 receptor [13]. AM6545 is a selective peripheral CB1-receptor antagonist. AM-6545 does not move through the barrier of the blood-brain [14]. Therefore, the aim of the study was to evaluate the function of cannabinoid CB1 receptors in diabetes-induced nephropathy.

\section{Methods}

\subsection{Reagents and chemicals}

Oleamide, a selective CB1 cannabinoid receptor agonist, and AM-6545, a selective peripheral CB1 receptor antagonist, were acquired from Sigma Chemicals Co., St. Louis, USA, with catalogue numbers O2136 and A1987.

\subsubsection{Insulin}

Insulin mixtrad 10 was purchased from Novo Nordisk, Denmark. All other chemicals were obtained are analytical grade from local commercial suppliers.

\subsection{Experimental animals}

The Institutional Animal Ethical Committee (Regd.No.516/ 01/2017/ACPCSEA) acknowledged the experimental protocol adopted in the present research. The rats were purchased from Hyderabad's Mahaveer enterprises. All the rats were housed with no more than three animals per cage in the institutional animal house and were kept on the regular chow diet and ad libitum water. Animals were subject to 12-h light and dark cycles. Uninephrectomy with thiopental sodium was performed as described below. For a total of 3 weeks, all the rats were able to recover. A single dose of STZ was given to rats at the end of the third week (55 m/kg, i.p., once).

\subsection{Uninephrectomy's function}

The influence of uninephrectomy on residual kidney enlargement is further exacerbated by a chronic insult from hyperglycemia. In addition, uninephrectomy stimulates diabetic glomerular injury and raises glomerular capillary pressure in rats. Compared with diabetic rats with intact kidneys, uninephrectomy accompanied by hyperglycemia accelerates the development of diabetic nephropathy [15].

\subsubsection{Procedure}

Surgical removal of the right kidney is included in the procedure. Thiopental sodium is used as anaesthesia agent in overnight fasting rats $(30 \mathrm{mg} / \mathrm{kg}$., i.p.). The rat was kept on the surgical bed, and with an animal fur trimmer, the hair was shaved. Using a surgical blade just under the rib cage on the right side, a small incision of about $2 \mathrm{~cm}$ in length was made. The skin was liberated from the adjoining connective tissue attached to the skin and the wall of the body. Along the body wall, a deeper cut was made. The kidney has been released from the adipose and fat tissues that surround it. The right kidney was revealed, and underneath the kidney, a string was attached. The kidney was now cut above the ligature, and the blood vessels attached to the thread were securely replaced in the cavity of the body. Using a 10-size curved needle, the body wall was carefully sutured with a digestible catgut suture and the skin was sutured with silk thread. The incision area was routinely swabbed with antiseptic lotion at each point of the operation. The suture area was treated with soframycin ointment on a daily basis for 1 week to avoid infections. For a total of 15 days, the rats were caged separately, then numbered and replaced with other species. Uninephrectomized animals were able to recover for 3 weeks before diabetes-mellitus induction.

\subsubsection{Type 1 diabetes mellitus induction}

Streptozotocin (STZ)-mediated pancreatic damage is widely used to establish rodent type 1 diabetes mellitus models. Eight-week-old Wistar rats of either sex were picked labelled, weighing (220-250 gms). They fasted overnight and STZ was freshly prepared by dissolving sodium citrate buffer of $\mathrm{pH} 4.5$ in freshly primed ice- 
cold sodium citrate. After dissolving into the buffer, the STZ disintegrates within $15-20 \mathrm{~min}$ and should therefore be administered immediately after preparation. One dose of STZ (55 mg/kg, i.p.,) [16] was administered after the STZ injection, and water supplemented with sucrose $(15 \mathrm{~g} / \mathrm{L})$ was given to rats for $48 \mathrm{~h}$ to minimize early mortality as insulin stores are released from weakened islets of the pancreas. One week after administering STZ, rats were tested for hyperglycaemia and animals with fasting blood glucose above $280 \mathrm{mg} / \mathrm{dL}$ were included in the study. To prevent the subsequent production of ketonuria, long-acting insulin (2-4 U/rat) was injected daily in diabetic rats to retain blood glucose levels in the anticipated range of $300-450 \mathrm{mg} / \mathrm{dL}$ until the experimental procedure was completed [15].

\subsection{Protocol for experimentation}

Animals with serum blood glucose levels above $280 \mathrm{mg} /$ $\mathrm{dL}$ were carefully chosen and labeled as diabetic rats, after 7 days of STZ administration and were included in the study. Oleamide and AM 6545 were given to uninephrectomised diabetic rats after 7 days of single STZ injection and treatment continued for 24 weeks. Both biochemical parameters in normal and uninephrectomised diabetic rats with or without drug treatment were evaluated at the end of the 24th week. Insulin mixtrad 10 (2-4 units/rat) was administered to all uninephrectomised diabetic rats with or without drug treatment to reduce mortality due to ketonuria. In uninephrectomised diabetic rats, with or without drug treatment, less than $10 \%$ of the mortality rate was observed.

\subsection{Grouping and treatment schedule}

Animals were divided into 11 groups $(n=10)$ and assigned as shown in Table 1.

\subsection{Estimation of biochemical parameters}

\subsubsection{Blood biochemical parameters assessment}

Colorimetric methods listed in detail in the supplementary material have been used to estimate blood glucose levels, serum creatinine, and blood urea nitrogen (BUN).

The assessment of urinary markers are as follows:

The microalbumin and the urine microproteins were estimated using ELISA kits.

2.6.1.1 Renal homogenate preparation The kidney was isolated and measured and washed in ice-cold isotonic saline. The weighted kidney was minced, and the icecold normal saline formed a homogenate $(1 \mathrm{~g} / 10 \mathrm{~mL})$. For estimating renal biomarkers, the homogenate thus obtained was used.

2.6.1.2 Renal collagen The total collagen content in the renal tissue homogenate was determined as per the method [17].

2.6.1.3 Renal hypertrophy Rats were sacrificed at the end of the 24th week by using sodium pentobarbitone at a dose of $200 \mathrm{mg} / \mathrm{kg}$ (i.p.), and the kidney was isolated and washed in ice-cold saline and weighed for renal hypertrophy calculation as measured in terms of the kidney weight to bodyweight ratio. Later, the kidney was homogenized to estimate the content of renal collagen, TNFalpha, and TGF1- $\beta$ : The ELISA method was used to estimate TNF-alpha (rat) and TGF- $\beta 1$ according to the instructions given in the manual. TGF-Beta ELISA kits with catalog no. 670 were acquired from the Cell Sciences Incorporation. A 020. 096., and ALPCO Diagnostics' TNF-alpha, Salem with catalog no. 45-TNFRT-E01.1.

\subsection{Statistical analysis}

All values obtained in the present analysis were expressed as mean \pm S.E.M. One-way ANOVA followed

Table 1 Grouping and treatment schedule

\begin{tabular}{|c|c|}
\hline S. No. group & Treatment \\
\hline I. Normal control & Rats were maintained on a standard diet without any treatment \\
\hline II. Diabetic control & Uninephrectomised rats were administered with STZ $(55 \mathrm{mg} / \mathrm{kg}$, single dose)+insulin (2-4 U/day) for 24 weeks \\
\hline III. Oleamide per se & Normal rats administered with oleamide $(5 \mathrm{mg} / \mathrm{kg}$, i.p) for 24 weeks \\
\hline IV. AM6545 per se & Normal rats were administered AM-6545 (16 mg/kg, i.p.) for 24 weeks \\
\hline V. Oleamide $1 \mathrm{mg} / \mathrm{kg}$ & The uninephrectomised diabetic rats treated with oleamide $(1 \mathrm{mg} / \mathrm{kg}$, i.p.) for 24 weeks \\
\hline Vl. Oleamide 2.5 mg/kg & The uninephrectomised diabetic rats treated with oleamide $(2.5 \mathrm{mg} / \mathrm{kg}$, i.p., $)$ for 24 weeks \\
\hline VII. Oleamide 5 mg/kg & The uninephrectomised diabetic rats treated with oleamide $(5 \mathrm{mg} / \mathrm{kg}$, i.p..) for 24 weeks \\
\hline VIII. AM-6545, 4mg/kg & The uninephrectomised diabetic rats treated with AM-6545 (4mg/kg, i.p.,) for 24 weeks \\
\hline IX. AM-6545, 8mg/kg & The uninephrectomised diabetic rats treated with AM-6545 (8mg/kg, i.p.) for 24 weeks \\
\hline X. AM-6545, 16mg/kg & The uninephrectomised diabetic rats treated with AM-6545 (16mg/kg, i.p.,) for 24 weeks \\
\hline XI. (Oleamide+AM-4565) & $\begin{array}{l}\text { The uninephrectomised diabetic rats treated with a combination of oleamide }(5 \mathrm{mg} / \mathrm{kg} \text {, i.p) and AM- } 6545 \\
(16 \mathrm{mg} / \mathrm{kg}) \text { for } 24 \text { weeks }\end{array}$ \\
\hline
\end{tabular}


by Tukey's multiple comparison test was used to evaluate the data obtained from different classes. The $p$ value was considered statistically significant at less than 0.05 . Statistical analysis was carried out using Graph pad prism (Version 8.0).

\subsection{Histology examination}

The histological evaluation was performed on rats picked at random from each group. The kidneys were immediately fixed with $10 \%$ formaldehyde buffered with phosphate. The kidney parts of 5- $\mu \mathrm{m}$ thickness are prepared with a microtome and stained with haematoxylin and eosin (H\&E) embedded in paraffin wax and examined with a phase-contrast microscope, Labomed (400X).

\section{Results}

\subsection{Effect of oleamide and AM-6545 on serum glucose levels}

The marked rise in serum blood glucose levels was observed in uninephrectomised diabetic rats when compared to normal rats at the end of the 24th week. However, treatment with oleamide $(1,2.5$ and $5 \mathrm{mg} / \mathrm{kg}$ i.p., for 24 weeks) did not modify the serum glucose concentration in uninephrectomised diabetic rats as shown in Table 2. Similarly, treatment with AM-6545 (4, 8 and $16 \mathrm{mg} / \mathrm{kg}$, i.p., for 24 weeks) did not affect serum glucose concentration in uninephrectomised diabetic rats shown in Table 2, suggesting that there was no influence of drug treatment on serum blood glucose.

\subsection{Effect of oleamide and AM- 6545 on the concentration of serum creatinine}

Serum creatinine in all uninephrectomised diabetic rats was significantly $(p<0.001)$ elevated compared to normal rats.

Uninephrectomized diabetic rats treated with oleamide $1 \mathrm{mg} / \mathrm{kg}$ and $2.5 \mathrm{mg} / \mathrm{kg}$ had no effect on serum creatinine. In addition, a partial rise in serum creatinine was witnessed in the uninephrectomised diabetic rats treated with oleamide $5 \mathrm{mg} / \mathrm{kg}$, but this increase was not statistically significant as shown in Fig. 1.

In comparison, treatment with AM-6545 $(4 \mathrm{mg} / \mathrm{kg}, 8$ $\mathrm{mg} / \mathrm{kg}, 16 \mathrm{mg} / \mathrm{kg}$, i.p.,) in uninephrectomised diabetic rats reported substantial reductions in serum creatinine levels $(p<0.005, p<0.005, p<0.001)$. In addition, the uninephrectomized diabetic rats treated with AM$6545(16 \mathrm{mg} / \mathrm{kg}$, i.p.) showed a significant decrease in serum creatinine levels compared to low dose $(4 \mathrm{mg} /$ $\mathrm{kg}$ and $8 \mathrm{mg} / \mathrm{kg})$ of AM-6545 as shown in Fig. $1(p<$ $0.005, p<0.005, p<0.001)$.

The concomitant administration of oleamide $(5 \mathrm{mg} / \mathrm{kg}$, i.p.) and AM-6545 (16 mg/kg, i.p.) produced a partial decrease in serum creatinine, but statistically not significant.

\subsection{Effect of oleamide and AM-6545 on blood urea nitrogen levels}

In uninephrectomised diabetic rats $(p<0.001)$, a marked rise in the blood urea nitrogen was observed relative to normal rats. Uninephrectomized diabetic rats administered with oleamide $1 \mathrm{mg} / \mathrm{kg}$ and $2.5 \mathrm{mg} / \mathrm{kg}$ have no effect on blood urea nitrogen. Oleamide $5 \mathrm{mg} / \mathrm{kg}$ therapy with partially elevated blood nitrogen urea. However, as shown in Fig. 2, this rise in BUN was not statistically important. Administration of AM-6545 $(4 \mathrm{mg} / \mathrm{kg}, 8 \mathrm{mg} / \mathrm{kg}$, $16 \mathrm{mg} / \mathrm{kg}$, i.p.) to uninephrectomised diabetic rats $(p<$ $0.005, p<0.005, p<0.001)$ significantly attenuated the rise in blood urea nitrogen levels caused by chronic diabetes. In addition, treatment with AM-6545 (8 mg/kg, i.p.) $)$ resulted in a significant decrease compared to AM-6545 (4 $\mathrm{mg} / \mathrm{kg}$, i.p.,) and with AM-6545 (16 mg/kg, i.p.,) caused in a significant reduction compared to AM-6545 (8 mg/ kg, i.p.,) in uninephrectomised diabetic rats (Fig. 2). In addition, concomitant administration of oleamide $(5 \mathrm{mg} /$ $\mathrm{kg}$, i.p.,) and AM-6545 (16 mg/kg, i.p.,) had no major effect on urea nitrogen in the blood (Fig. 2).

Table 2 Serum blood glucose levels in various groups

\begin{tabular}{lll}
\hline Groups & Serum glucose (mg/dL) & Percent mortality \\
\hline Group I (normal group) & $100.45 \pm 5.94$ & 10 \\
Group II (uninephrectomised diabetic group) & $429.44 \pm 4.18^{\mathrm{a}}$ & $104.63 \pm 4.47$ \\
Group III (oleamide per se) & $102.21 \pm 3.93$ & 10 \\
Group IV (AM-6545 per se) & $420.16 \pm 7.21$ & 10 \\
Group V (oleamide $1 \mathrm{mg} / \mathrm{kg}$ treated group) & $432.58 \pm 5.12$ & 10 \\
Group VI (oleamide $2.5 \mathrm{mg} / \mathrm{kg}$ treated group) & $425.76 \pm 4.56$ & 10 \\
Group VII (oleamide $5 \mathrm{mg} / \mathrm{kg}$ treated group) & $428.43 \pm 5.27$ & 10 \\
Group VIII (AM-6545 $4 \mathrm{mg} / \mathrm{kg}$ treated group) & $430.72 \pm 3.37$ & 10 \\
Group IX (AM-6545 $8 \mathrm{mg} / \mathrm{kg}$ treated group) & $411.76 \pm 8.22$ & 10 \\
Group X (AM-6545 $16 \mathrm{mg} / \mathrm{kg}$ treated group) & $419.66 \pm 3.96$ & \\
Group XI (oleamide $5 \mathrm{mg} / \mathrm{kg}+$ AM-6545 16 mg/kg treated group) & \\
\hline
\end{tabular}

${ }^{\mathrm{a}}$ Serum blood glucose levels were elevated significantly $(p<0.001)$ when compared to normal group 


\section{SERUM CREATININE (mg/dL)}

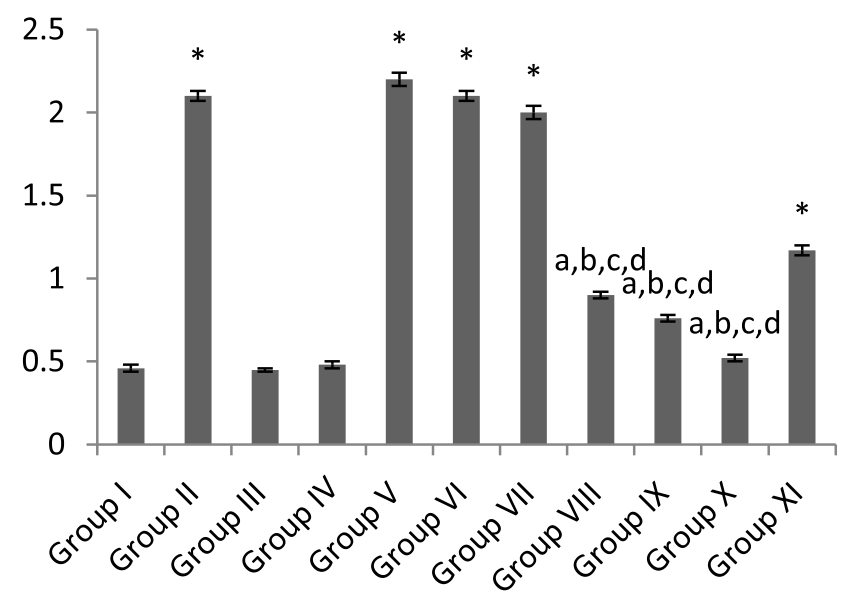

- SERUM CREATININE $(\mathrm{mg} / \mathrm{dL})$

Fig. 1 Graph representing serum creatinine levels ( $\mathrm{mg} / \mathrm{dL}$ ). All values were shown as mean $\pm \mathrm{SEM}$. ${ }^{*}=p<0.001$ versus group I (normal control); $a$ $=p<0.005$ versus group II (uninephrectomised diabetic control); $b=p<0.005$ versus group V (uninephrectomised diabetic rats with oleamide $(1 \mathrm{mg} / \mathrm{kg})$ treatment; $c=p<0.005$ versus group VI (uninephrectomised diabetic rats with oleamide $(2.5 \mathrm{mg} / \mathrm{kg})$ treatment); $d=p<0.001 \mathrm{versus}$ group VII (uninephrectomised diabetic rats with oleomide $(5 \mathrm{mg} / \mathrm{kg})$ treatment)

\subsection{Effect of oleamide and AM-6545 on urinary} microprotein levels

Compared to normal rats, a substantial $(p<0.001)$ raise in urinary protein excretion was observed in uninephrectomised diabetic rats.

Treatment of uninephrectomised diabetic rats with oleamide $(1 \mathrm{mg} / \mathrm{kg}$ and $2.5 \mathrm{mg} / \mathrm{kg}$, i.p.) has no effect on microprotein urinary excretion. Oleamide $5 \mathrm{mg} / \mathrm{kg}$ therapy partially elevated urinary protein levels; this rise in urinary microprotein, however, was not statistically significant.
Administration of AM-6545 (4 mg/kg, $8 \mathrm{mg} / \mathrm{kg}, 16 \mathrm{mg} /$ $\mathrm{kg}$ ) to uninephrectomized diabetic rats significantly decreased the level of urinary microprotein elevation caused by diabetes. In addition, treatment with AM-6545 (8 mg/ $\mathrm{kg}$, i.p.) resulted in a substantial decrease in proteinuria $(p<0.001)$ relative to $\mathrm{AM}-6545$ ( $4 \mathrm{mg} / \mathrm{kg}$, i.p., $)(p<0.001)$ and AM-6545 (16 mg/kg, i.p.,) produced a marked decrease $(p<0.0001)$ in proteinuria compared to AM-6545 (8 $\mathrm{mg} / \mathrm{kg}$, i.p.,) in uninephrectomized diabetic rats (Fig. 3). Furthermore, concomitant administration of oleamide (5

\section{Blood Urea Nitrogen (BUN) mg/dL}

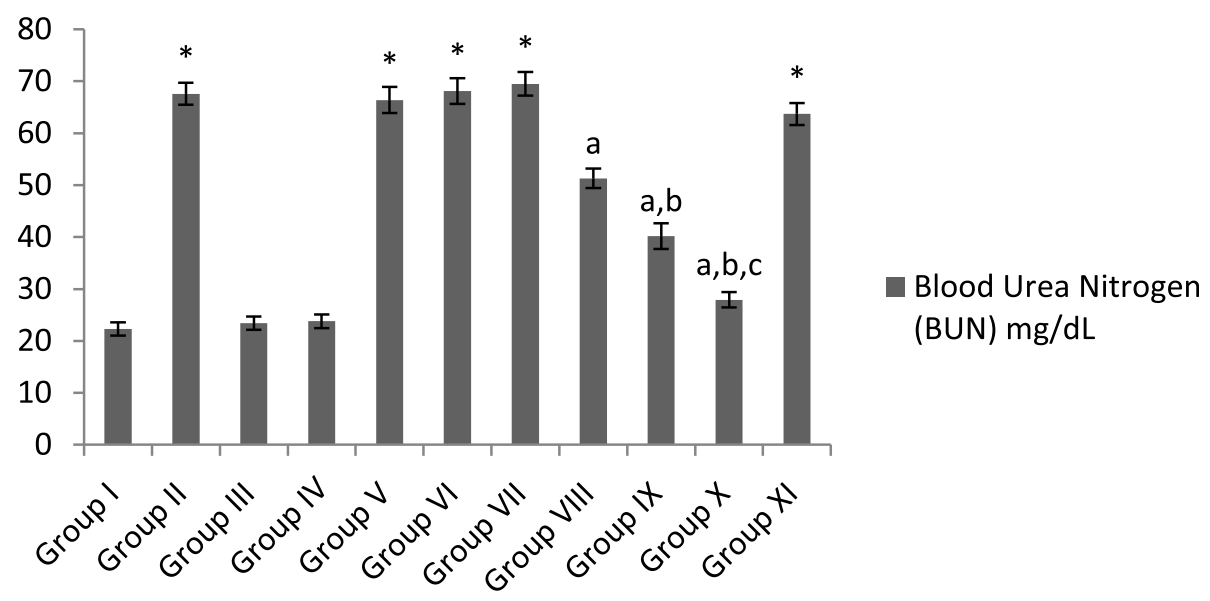

Fig. 2 Graph representing blood urea nitrogen levels (mg/dL). All values were represented as mean $\pm \mathrm{SEM} .{ }^{*}=p<0.001$ versus group I (normal control); $a=p<0.001$ versus group II (uninephrectomised diabetic control); $b=p<0.005$ versus group V (uninephrectomised diabetic rats with oleamide ( $1 \mathrm{mg} / \mathrm{kg}$ ) treatment; $c=p<0.005$ versus group VI (uninephrectomised diabetic rats with oleamide $(2.5 \mathrm{mg} / \mathrm{kg})$ treatment); $d=p<$ 0.001 versus group VI (uninephrectomised diabetic rats with oleomide $(5 \mathrm{mg} / \mathrm{kg}$ ) treatment) 


\section{Urinary Microprotein (mg/24hrs)}

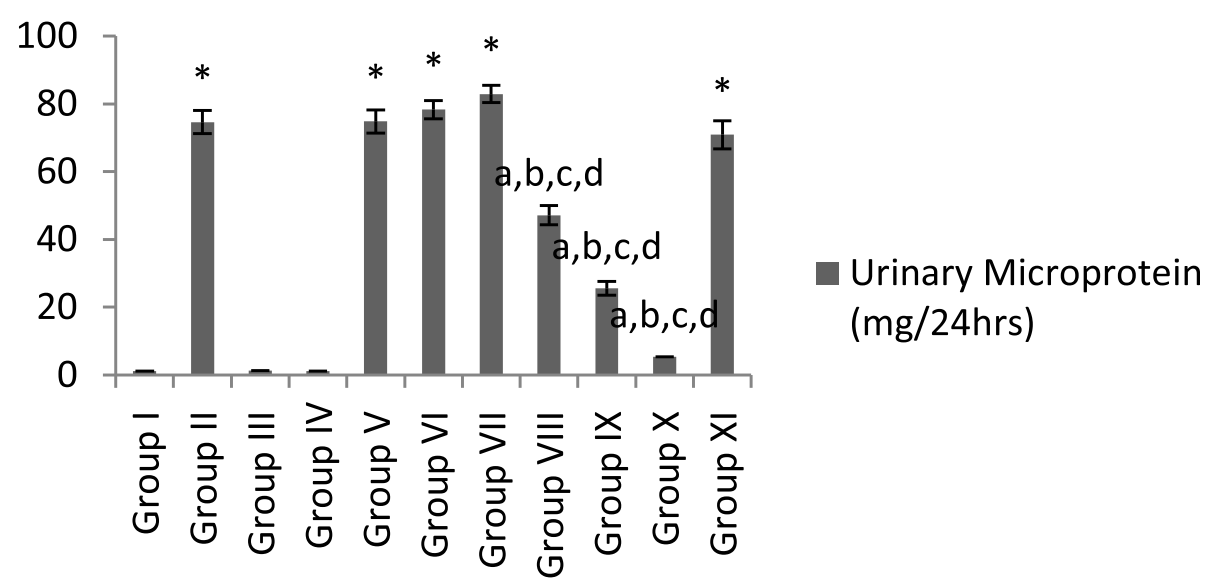

Fig. 3 Graph representing urinary microprotein levels (mg/24h). All values were represented as mean \pm SEM. ${ }^{*}=p<0.001$ versus group I (normal control); $a=p<0.001$ versus group II (uninephrectomised diabetic control); $b=p<0.001$ versus group V (uninephrectomised diabetic rats with oleamide $(1 \mathrm{mg} / \mathrm{kg})$ treatment; $c=p<0.001$ versus group VI (uninephrectomised diabetic rats with oleamide $(2.5 \mathrm{mg} / \mathrm{kg})$ treatment); $d=p<$ 0.0001 versus group VI (uninephrectomised diabetic rats with oleomide ( $5 \mathrm{mg} / \mathrm{kg}$ ) treatment)

$\mathrm{mg} / \mathrm{kg}$, i.p.) and AM-6545 (16 mg/kg, i.p.,) did not produce any important proteinuria effect.

\subsection{Effect of oleamide and AM-6545 on urinary excretion of albumin}

In contrast to normal rats, a pronounced elevation in albuminuria was observed in uninephrectomised diabetic rats $(p<0.001)$. Oleamide therapy $(1 \mathrm{mg} / \mathrm{kg}$ and $2.5 \mathrm{mg} /$ kg; i.p., for 24 weeks) had no impact on urinary excretion of albumin in diabetic uninephrectomised rats. However, statistically insignificant elevations of albumin in urine were observed in uninephrectomised diabetic rats treated with oleamide ( $5 \mathrm{mg} / \mathrm{kg}$; i.p., 24 weeks).

Administration of AM 6545 (4 mg/kg, $8 \mathrm{mg} / \mathrm{kg}, 16 \mathrm{mg} /$ $\mathrm{kg}$, i.p., for 24 weeks) to uninephrectomised diabetic rats substantially decreased the elevation of albuminuria caused by diabetes. In addition, AM-6545 (16 mg/kg; i.p., for 24 weeks) demonstrated a substantial reno-protective potential $(p<0.005,<0.005,<0.0001)$ by significantly decreasing albuminuria as graphically depicted in uninephrectomized diabetic rats. No significant changes were found in urinary albumin excretion by simultaneous administration of oleamide (5 mg/kg; i.p., for 24 weeks) and AM-6545 (16 mg/kg; i.p., for 24 weeks) (Fig. 4).

\subsection{Effect of oleamide and AM-6545 on renal collagen expression}

Compared to normal rats, a substantial $(p<0.001)$ increase in renal collagen content was observed in uninephrectomised diabetic rats. Treatment with oleamide $(1 \mathrm{mg} / \mathrm{kg}$,
$2.5 \mathrm{mg} / \mathrm{kg}$ and $5 \mathrm{mg} / \mathrm{kg}$, i.p. for 24 weeks) did not produce a major impact on the content of renal collagen. Administration of AM-6545 (4 mg/kg, $8 \mathrm{mg} / \mathrm{kg}, 16 \mathrm{mg} / \mathrm{kg}$; i.p., 24 weeks) showed a substantial decrease in collagen content $(p<0.005, p<0.001, p<0.001)$ compared with that of uninephrectomised diabetic rats. Furthermore, in uninephrectomised diabetic rats, treatment with AM-6545 (16 mg/kg, i.p., for 24 weeks) resulted in a substantial reduction in collagen content. Concurrent administration of oleamide (5 mg/kg, i.p., 24 weeks) + AM-6545 (16 mg/kg, i.p., 24 weeks) did not have a major impact on the expression of renal collagen (Fig. 5).

\subsection{Effect of oleamide and AM-6545 on renal hypertrophy} In contrast to standard rats, uninephrectomised diabetic rats displayed pronounced renal hypertrophy $(p<$ $0.005)$. No major effect on renal hypertrophy was observed with oleamide $(1 \mathrm{mg} / \mathrm{kg}, 2.5 \mathrm{mg} / \mathrm{kg}$ and $5 \mathrm{mg} /$ $\mathrm{kg}$; i.p., for 24 weeks) therapy. AM-6545 (4 mg/kg, 8 $\mathrm{mg} / \mathrm{kg}, 16 \mathrm{mg} / \mathrm{kg}$; i.p., 24 weeks $)(p<0.005, p<0.005$, $0.005)$ reported a substantial decrease in kidney hypertrophy compared with uninephrectomised diabetic rats. In addition, in uninephrectomised diabetic rats, administration of AM-6545 (16 mg/kg, i.p., for 24 weeks) showed a marked decrease in renal hypertrophy. Concurrent administration of oleamide $(5 \mathrm{mg} /$ kg; i.p., 24 weeks $)$ + AM-6545 (16 mg/kg, i.p., 24 weeks) has no important impact on renal hypertrophy, as shown in Fig. 6, graphically. 


\section{Urinary Albumin (mg/dL)}

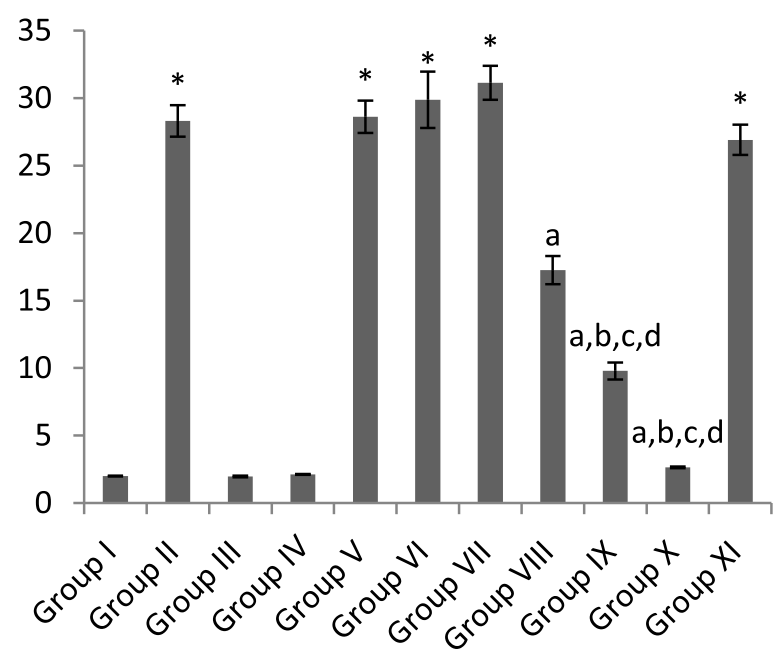

- Urinary Albumin (mg/dL)

Fig. 4 Graph representing urine albumin levels (mg/dL). All values were represented as mean \pm SEM. ${ }^{*}=p<0.001$ versus group I (normal control); $a=p<0.001$ versus group II (uninephrectomised diabetic control); $b=p<0.005$ versus group $\vee$ (uninephrectomised diabetic rats with oleamide $(1 \mathrm{mg} / \mathrm{kg}$ ) treatment; $c=p<0.005$ versus group VI (uninephrectomised diabetic rats with oleamide $(2.5 \mathrm{mg} / \mathrm{kg})$ treatment); $d=p<$ 0.001 versus group VI (uninephrectomised diabetic rats with oleomide $(5 \mathrm{mg} / \mathrm{kg})$ treatment)

\subsection{Effect of oleamide and AM-6545 on renal tumor}

\section{necrosis factor-alpha (TNF-alpha) concentration}

In uninephrectomised diabetic rats, a markedly significant $(p<0.001)$ rise in renal tumour necrosis factor-alpha (TNF-alpha) was observed compared to normal rats (Table 2). Oleamide-treated uninephrectomised diabetic rats $(1 \mathrm{mg} / \mathrm{kg}$, i.p., for 24 weeks) showed no effect on TNF-alpha levels. Oleamide administration $(2.5 \mathrm{mg} / \mathrm{kg}$ and $5 \mathrm{mg} / \mathrm{kg}$, i.p., for 24 weeks) in uninephrectomised diabetic rats, on the other hand, showed a substantial increase in TNF-alpha relative to uninephrectomised diabetic rats without care. In uninephrectomised diabetic

\section{Renal Collagen $(\mu \mathrm{g} / \mathrm{mg})$}

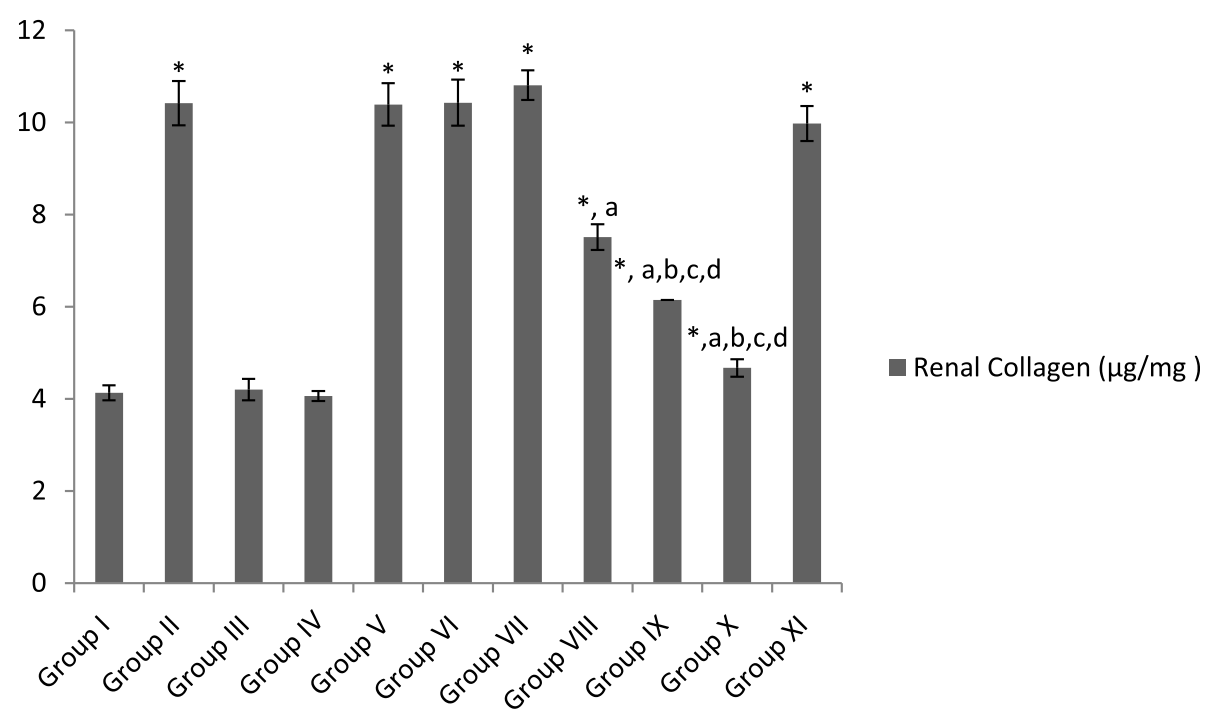

Fig. 5 Graph representing renal collagen levels $\left(\mu \mathrm{g} / \mathrm{mg}\right.$ ). All values were represented as mean \pm SEM. ${ }^{*}=p<0.001$ versus group I (normal control); $a=p<0.001$ versus group II (uninephrectomised diabetic control); $b=p<0.005$ versus group $V$ (uninephrectomised diabetic rats with oleamide $(1 \mathrm{mg} / \mathrm{kg}$ ) treatment; $c=p<0.001$ versus group VI (uninephrectomised diabetic rats with oleamide $(2.5 \mathrm{mg} / \mathrm{kg})$ treatment); $d=p<$ 0.001 versus group VI (uninephrectomised diabetic rats with oleomide $(5 \mathrm{mg} / \mathrm{kg})$ treatment) 


\section{Renal hypertrophy (mg/gm)}

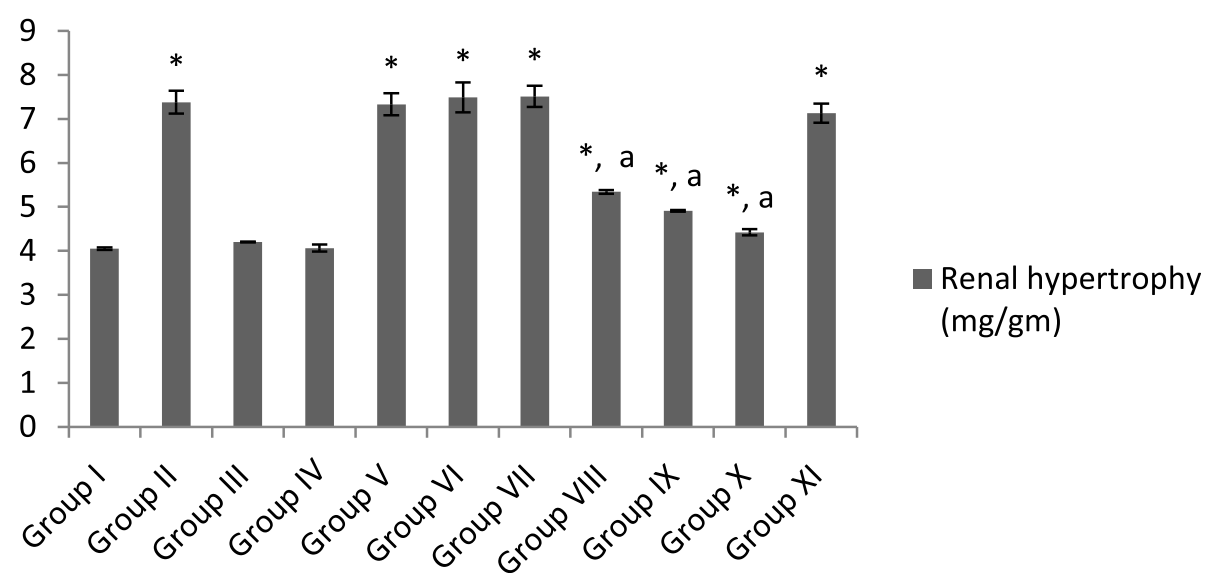

Fig. 6 Graph representing renal hypertrophy levels (mg/gm). All values were represented as mean \pm SEM. ${ }^{*}=p<0.005$ versus group I (normal control); $a=p<0.005$ versus group II (uninephrectomised diabetic control)

rats, treatment of AM-6545 $(4 \mathrm{mg} / \mathrm{kg}, 8 \mathrm{mg} / \mathrm{kg}, 16$ $\mathrm{mg} / \mathrm{kg}$, i.p., for 24 weeks) showed a substantial decrease $(\mathrm{p}<0.005,<0.005,<0.005)$ in serum TNF-alpha relative to uninephrectomised diabetic rats. In addition, AM-6545 (16 mg/kg, i.p., for 24 weeks) showed a substantial decrease in TNF-alpha compared to $4 \mathrm{mg} / \mathrm{kg}$ and $8 \mathrm{mg} / \mathrm{kg}$, i.p., of uninephrectomised diabetic rats treated with AM6545. Concurrent administration of oleamide $(5 \mathrm{mg} / \mathrm{kg}$, i.p., for 24 weeks $)$ and AM-6545 (16 mg/kg, i.p., for 24 weeks) in uninephrectomised diabetic rats had no effect on the expression of TNF-alpha (Fig. 7).
3.9 Effect of oleamide and AM-6545 on renal transforming growth factor-beta

\subsection{1 (TGF-beta) concentration}

Compared to normal rats with intact kidneys, a substantial increase in TGF- $\beta$ was observed in uninephrectomised diabetic rats $(p<0.001)$. The administration of oleamide to uninephrectomised diabetic rats $(1 \mathrm{mg} / \mathrm{kg}$ and $2.5 \mathrm{mg} / \mathrm{kg}$, i.p., for 24 weeks) showed a partial increase in TGF- $\beta$ levels. This rise in TGF- $\beta$ was, however, statistically significant $(p<0.001)$. In addition, oleamide administration $(5 \mathrm{mg} / \mathrm{kg}$, i.p. for 24 weeks) showed a substantial improvement in renal TGF-beta levels $(p<$

\section{Renal TNF- $\alpha(p g / m l)$}

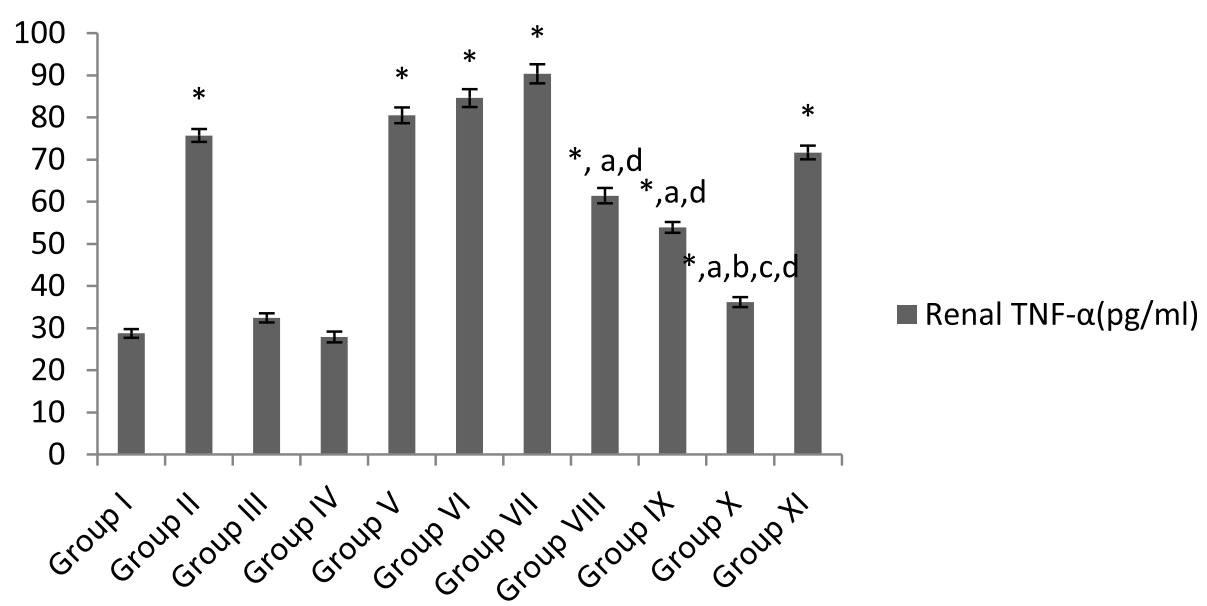

Fig. 7 Graph representing TNF-a levels (pg/ml). All values were represented as mean $\pm \mathrm{SEM}$. ${ }^{*}=p<0.001$ versus group I (normal control); $a=p<$ 0.001 versus group II (uninephrectomised diabetic control); $b=p<0.005$ versus group V (uninephrectomised diabetic rats with oleamide (1 mg/ $\mathrm{kg}$ ) treatment); $c=p<0.005$ versus group VI (uninephrectomised diabetic rats with oleamide $(2.5 \mathrm{mg} / \mathrm{kg})$ treatment); $d=p<0.005$ versus group $\mathrm{VI}$ (uninephrectomised diabetic rats with oleomide $(5 \mathrm{mg} / \mathrm{kg})$ treatment) 
$0.001)$ relative to untreated diabetic rats. There was a substantial decrease in TGF- $\beta$ in uninephrectomised diabetic rats treated with AM-6545 $(4 \mathrm{mg} / \mathrm{kg}, 8 \mathrm{mg} / \mathrm{kg}$ and $16 \mathrm{mg} / \mathrm{kg}$, i.p., for 24 weeks) $(p<0.005,0<0.005,<0.005)$ relative to untreated uninephrectomised diabetic rats. Additionally, administration of AM-6545 (16 mg/kg i.p. for 24 weeks) to uninephrectomised diabetic rats showed a substantial decrease in TGF-beta relative to administration of AM-6545 (4 mg/kg and $8 \mathrm{mg} / \mathrm{kg}$ i.p. for 24 weeks) to uninephrectomised diabetic rats. The concomitant administration of oleamide $(5 \mathrm{mg} / \mathrm{kg}$, i.p., 24 weeks) and AM-6545 (16 mg/kg, i.p., 24 weeks) did not show any effect on TGF- $\beta$ expression (Fig. 8).

\subsection{Effect of oleamide and AM-6545 on histopathological changes}

The histopathology of the kidney parts was interpreted by the Labomed phase-contrast microscope (400X). Group I rats displayed natural renal tissue histology. Uninephrectomized group II rats revealed compromised histology with shrunken and expanded space of the bowman, basement membrane thickening, monocyte infiltration, convoluted tubule dilation, and interstitial lesions of diffuse mesangial matrix cells. Animals treated with oleamide revealed weakened glomerular membrane with leakage and showed no improvement in renal morphology, while rats treated with AM-6545 showed improved renal cell-matrix morphology, peri-tubular and glomerular lesions were reduced, and normal histology was preserved at high doses of AM6545 $(16 \mathrm{mg} / \mathrm{kg})$. Histological changes were not observed with combination of oleamide and AM6545 (Fig. 9).

\section{Discussion}

In this study, CB1 agonist-oleamide and CB1 antagonist AM6545 combined therapy did not relieve the pathological symptoms, but CB1 blocker AM6545 alone offered substantial safety in experimental diabetic nephropathy, and this is due to CB1 receptor blockade. This study showed that in diabetic nephropathy, CB1 inhibition provided substantial defense against serum creatinine, blood urea nitrogen, albuminuria, renal collagen, inflammation and proteinuria, while in experimental diabetic nephropathy, CB1 agonist oleamide upregulated renal damage biomarkers signifying upregulation of $\mathrm{CB} 1$ receptor expression.

The key characteristic of diabetic nephropathy is reduced glomerular filtration due to glomerular injury with gradual mesangial expansion following the onset of hyperglycemia [18]. In diabetic nephropathy, endocannabinoid systems (ECS) seem to play a prominent role. Via Gi/o proteins, the cannabinoid receptor (CB1) negatively coupled with adenylate cyclase and modulates different ion channels. These CB1 receptors are highly peripherally expressed and have many functions, such as lipid metabolism and energy storage [19].

It was also found that the podocyte cells of diabetic glomeruli are highly upregulated by CB1 receptors. This overexpression results in podocyte injury with pronounced loss of proteinuria and nephrin [20].

Albuminuria and renal fibrosis have been shown to improve with a combination of the CB1 blocker AM6545 and the CB2 agonist AM1241 [21]. Data from past studies has also shown that CB1 blockade can reverse changes induced by diabetes [22].

\section{Renal TGF-1 $\beta(\mu \mathrm{g} / \mathrm{ml})$}

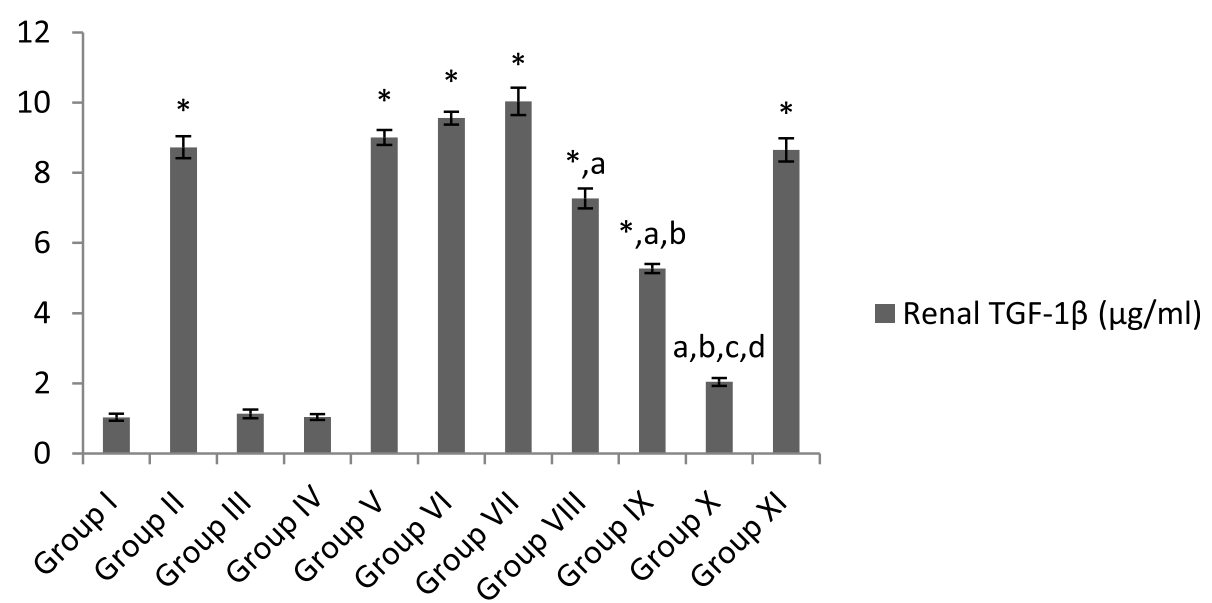

Fig. 8 Graph representing TGF- $\beta$ levels $(\mu \mathrm{g} / \mathrm{ml})$. All values were represented as mean $\pm \mathrm{SEM} .{ }^{*}=p<0.001$ versus group I (normal control); $a=p$ $<0.001$ versus group II (uninephrectomised diabetic control); $b=p<0.005$ versus group $V$ (uninephrectomised diabetic rats with oleamide $(1 \mathrm{mg} / \mathrm{kg})$ treatment; $c=p<0.005$ versus group VI (uninephrectomised diabetic rats with oleamide $(2.5 \mathrm{mg} / \mathrm{kg})$ treatment); $d=p<0.005$ versus group VI (uninephrectomised diabetic rats with oleomide $(5 \mathrm{mg} / \mathrm{kg}$ ) treatment) 
A.

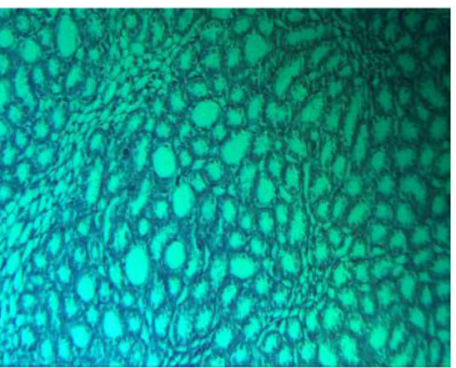

D.

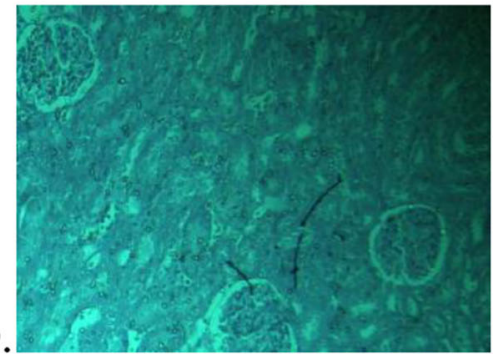

B.

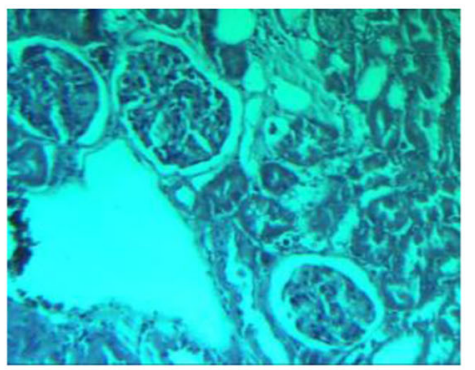

E.

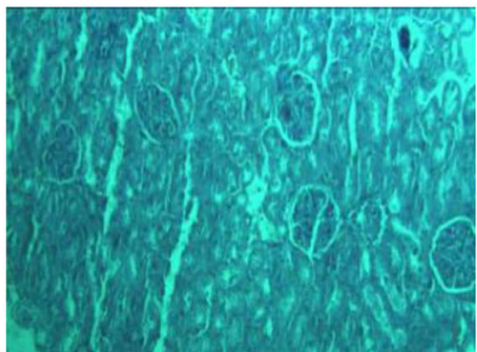

C.

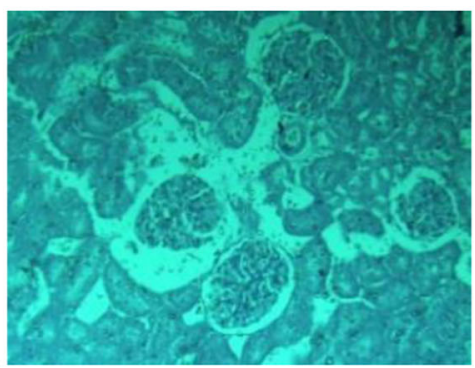

Fig. 9 a Normal control. b Disease control. c Oleamide (5mg/kg). d AM6545 (16mg/kg). e Oleamide (5mg/kg)+AM6545 (16mg/kg)

Activation of the CB1 receptor also stimulates Gs proteins and raises the levels of intracellular calcium. The renal podocytes express CB1 receptors, and the angiotensin-II receptor subtype induces signalling. Increased activation of the $\mathrm{CB} 1$ receptor contributes to proteinuria by nephrin downregulation [19]. In addition, activation of the CB1 receptor often releases inflammatory cytokines such as TNF-alpha, MCP-1, which further produce nephrin loss and increases the expression of components of the extracellular matrix [19]. In hyperglycaemia, CB1 receptors are also known to lead to interstitial fibrosis [23].

It has been found that clinical proteinuria has an association with diabetic glomerulosclerosis. The mechanisms involved in the occurrence of proteinuria in diabetic patients have been postulated to be augmented glomerular filtration rate, inadequate tubular absorption, overflow and augmented tubular secretion [24]. In diabetic nephropathy, structural anomalies preceding the onset of proteinuria include increased basement membrane width and mesangial expansion [25]. Furthermore, amplified collagen synthesis by podocytes can lead to glomerular basement thickening, and excessive amounts of secreted vascular endothelial growth factor can increase macromolecular barrier permeability [26]. A typical podocytopathy occurs in the glomerulus in the diabetic kidney, which is involved in the acceleration of plasma protein leakage through the glomerular basement membrane. The incidence of proteinuria caused by diabetes also persuades tubular cell inflammation to ease the advance of interstitial fibrosis and tubular atrophy [27]. Decreased podocyte density due to apoptosis and thickening of the glomerular basement membrane with transformed matrix composition, decreased slit diaphragm nephrin levels result in diabetic podocytopathy clinically revealed as albuminuria and proteinuria [28]. The presence of proteins in urine as an index of renal dysfunction in diabetic nephropathy has been indicated by clinical and experimental evidence [29]. Increased urinary protein excretion in uninephrectomised diabetic rats was observed in the current study, and in uninephrectomised diabetic rats, treatment with AM-6545 caused a substantial reduction in proteinuria.

In diabetic nephropathy, unremitting inflammation and fibrogenesis contribute to the production of kidney damage [30]. Extracellular matrix micro-inflammation and expansion are typical pathways associated with DN progression. Different molecular forms, such as proinflammatory cytokines, chemokines, adipokines and adhesion molecules, are known to be associated with DN [31]. Data from previous studies have also shown that CB1 receptors have pro-inflammatory and pro-fibrotic effects [32].

Activated macrophages develop a wide range of potentially cytotoxic elements that lead to renal injury, including TNF-alpha (Fig. 7) and TGF $\beta$ (Fig. 8). A main driving force of micro-inflammation is TNF-alpha. It induces pro-inflammatory effects by binding resident cells to TNF-receptors [33]. TNF-alpha induces NADPH oxidase and increases oxidative stress by inducing the development of ROS [34, 35]. TNF-alpha also increases the production of nitric oxide and ultimately cytotoxicity [36], works with TGF- $\beta$ and stimulates the deposition of extracellular matrix components [37]. These events contribute to improvements in the rate of glomerular filtration and endothelial permeability of diabetic kidneys. 
The permeability of albumin through the glomerular filter is controlled exclusively by discrimination in size. The bulk of filtered albumin is recovered and resumed to the peritubular blood supply by the proximal tubular cell. Albuminuria is a consequence of this retrieval pathway dysfunction. Minor amounts of unrecovered filtered albumin undertake compulsory lysosomal degradation as small fragments of peptides prior to urinary excretion [38] This phase is susceptible to various hypertrophy and fibrosis-related metabolic factors, namely angiotensin II and transforming growth factor-beta1, the generation of which is triggered by hyperglycemic conditions. TGF- $\beta$ activates renal podocytes and, through the PI3K pathway, induces MCP-1 expression. By activating the CCR2 receptor, the released MCP-1 affects back the podocytes and making it more motile cause actin cytoskeletal changes such that the podocyte network hyperpermeability of albumin and ultimately implications for diabetic albuminuria [39].

AM-251 blockade of the CB1 receptor substantially attenuated the rat model's rise in proteinuria [12]. Further administration of AM-251 (a specific CB1 receptor antagonist) substantially weakened the increase in albuminuria and nephropathy in diabetic nephropathy rodents due to diabetes [40]. Administration of SR141716 (a specific CB1 receptor antagonist) also significantly attenuated diabetes-induced nephropathy, demonstrated by a substantial decrease in urinary albuminuria excretion in $\mathrm{db} / \mathrm{db}$ mice [41].

In addition, increased glucose is associated with enhanced hypertrophy and type IV collagen synthesis in rat culture mesangial cells, indicating that cellular hypertrophy and extracellular matrix synthesis can play a key role in diabetic nephropathy pathogenesis [42]. Our observations are in line with literature from the past. In diabetic nephropathy, CB1 antagonist AM-6545 (16mg/ $\mathrm{kg}$ ) decreased renal fibrosis; this may be due to TGF- $\beta /$ MCP-1 signalling.

This research delineates the reno-protective potential of a peripheral CB1 receptor antagonist named AM6545. In addition, the AM-6545 compound is a neutral CB1 receptor antagonist and demonstrates limited access to the CNS. Only the central side effects (depression and nausea) caused by the classical CB1 receptor antagonists were removed using this compound. For histopathologic alterations in kidney tissue, the research was further evaluated. The usual histology of renal tissue relative to DN rats and oleamide-treated rats was normal for treatment with AM6545.

\section{Conclusions}

The findings of the current study indicate that treatment with CB1 agonist oleamide did not produce any improvements in diabetic nephropathy, while treatment with $\mathrm{CB} 1$ antagonist did not produce renoprotection by attenuating inflammatory mediators such as TNF-alpha, TGF $\beta$. Serum creatinines, blood urea nitrogen levels with CB1 antagonism, were also normalized. Along with decreases in urinary microproteins and renal collagen and renal hypertrophy, AM6545 provided substantial protection against albuminuria. Keeping in mind that, as observed in the current study, AM6545 has broad renoprotective properties, its use can correct and delay DN progression. However, in order to understand the comprehensive mechanisms and pharmacotherapy of AM6545, further preclinical and clinical research studies are needed.

\section{Abbreviations}

ANOVA: Analysis of variance; CCR2: C-C chemokine receptor type 2; DN: Diabetic nephropathy; ECS: Endocannabinoid system; ELISA: Enzymelinked immunosorbent assay; GFR: Glomerular filtration rate; MCP1: Moonocyte chemoattraction protein-1; NADPH: Nicotinamide adenine dinucleotide phosphate; ROS: Reactive oxygen species; STZ: Streptozotocin; TGF- $\beta$ : Transforming growth factor-beta; TNF-a: Tumor necrosis factor-alpha

\section{Supplementary Information}

The online version contains supplementary material available at https://doi. org/10.1186/s43088-021-00121-y

Additional file 1. Detailed procedures for estimation of biochemical parameters.

\section{Acknowledgements}

The authors thank the Andhra University authorities for providing the required facilities to carry out the research work.

\section{Authors' contributions}

J R M-Carried out the work. D R-Paper drafting and data analyse. V R B-Paper drafting and editing. S K R-Histopathological studies. G S G-Supervision. A A-Conceptualisation. The authors have read and approved the manuscript.

Funding

Indian Council of Medical Research (ICMR) - IRIS ID - 02440 (Role of the funder. The fellowship was awarded to pursue Doctor of Philosophy).

Availability of data and materials

Submitted along with manuscript.

\section{Declarations}

Ethics approval and consent to participate

Regd.No.516/01/2017/ACPCSEA), New Delhi, India, and approved by the Institutional Animal Ethical Committee (IAEC), Andhra University,

Visakhapatnam.

Consent for publication

Not applicable.

Competing interests

The authors declare that they have no competing interests.

Author details

${ }^{1} \mathrm{~A} \cup$ College of Pharmaceutical Sciences, Andhra University, Visakhapatnam, Andhra Pradesh 530003, India. ${ }^{2}$ Pharmacology Division, Vignan Institute of Pharmacuetical Technology, Duvvada, Visakhapatnam, India. 
Received: 23 October 2020 Accepted: 3 May 2021

\section{Published online: 26 May 2021}

\section{References}

1. Balakumar P, Chakkarwar VA, Singh M (2009a) Ameliorative effect of combination of benfotiamine and fenofibrate in diabetes-induced vascular endothelial dysfunction and nephropathy in the rat. Mol Cell Biochem 320(1-2):149-162. https://doi.org/10.1007/s11010-008-9917-z

2. Mauer SM (1994) Structural-functional correlations of diabetic nephropathy. Kidney Int 45(2):612-622. https://doi.org/10.1038/ki.1994.80

3. Wolf G (2000) Cell cycle regulation in diabetic nephropathy. Kidney Int Suppl 7(7):S59-S66

4. Balakumar P, Chakkarwar VA, Krishan P, Singh M (2009b) Vascular endothelial dysfunction: a tug of war in diabetic nephropathy? Biomed Pharmacother 63(3):171-179. https://doi.org/10.1016/j.biopha.2008.08.008

5. Gruden G, Barutta F, Kunos G, Pacher P (2016) Role of the endocannabinoid system in diabetes and diabetic complications. Br J Pharmacol 173(7):11161127. https://doi.org/10.1111/bph.13226

6. Viveros MP, Bermúdez-Silva FJ, Lopez-Rodriguez AB, Wagner EJ (2011) The endocannabinoid system as pharmacological target derived from its CNS role in energy homeostasis and reward. Applications in eating disorders and addiction. Pharmaceuticals 4(8):1101-1136. https://doi.org/10.3390/ph40811 01

7. de Fonseca FR, Del Arco I, Bermudez-silva FJ, Bilbao A, Cippetelli A, Navarro $M$ et al (2005) The endocannabinoid system: physiology and pharmacology. Alcohol Alcohol 40(1):2-14. https://doi.org/10.1093/alcalc/agh110

8. Malenczyk K, Jazurek M, Keimpema E, Silvestri C, Janikiewicz J, Mackie K, di Marzo V, Redowicz MJ, Harkany T, Dobrzyn A (2013) CB1 cannabinoid receptors couple to focal adhesion kinase to control insulin release. J Biol Chem 288(45):32685-32699. https://doi.org/10.1074/jbc.M113.478354

9. Mukhopadhyay P, Pan H, Rajesh M, Batkai S, Patel V, Harvey-White J et al (2010) CB1 cannabinoid receptors promote oxidative/nitrosative stress, inflammation and cell death in a murine nephropathy model. $\mathrm{Br} J$ Pharmacol 160(3):657-668. https://doi.org/10.1111/j.1476-5381.2010.00769.x

10. Larrinaga G, Varona A, Perez I, Sanz B, Ugalde A, Candenas ML et al (2010) Expression of cannabinoid receptors in human kidney. Histol Histopathol 25(9):1133-1138. https://doi.org/10.14670/HH-25.1133

11. Barutta F, Grimaldi S, Franco I, Bellini S, Roberto G, Pinach S, Corbelli A, Bruno G, Rastaldi MP, Aveta T, Hirsch E, Marzo VD, Gruden G (2014) Defiency of cannabinoid receptor of type 2 worsens renal functional and structural abnormalities in Streptozotocin-induced diabetic mice. Kidney Int 86(5):979-990. https://doi.org/10.1038/ki.2014.165

12. Janiak P, Poirier B, Bidouard JP, Cadrouvele C, Pierre F, Gouraud L, Barbosa I, Dedio J, Maffrand JP, le Fur G, O'Connor S, Herbert JM (2007) Blockade of cannabinoid CB1 receptors improves renal function, metabolic profile, and increased survival of obese Zucker rats. Kidney Int 72(11):1345-1357. https:// doi.org/10.1038/sj.ki.5002540

13. Hill MN, Gorzalka BB (2005) Is there a role for the Endocannabinoid system in the etiology and treatment of melancholic depression? Behav Pharmacol 16(5-6):333-352. https://doi.org/10.1097/00008877-200509000-00006

14. Cluny NL, Vemuri VK, Chambers AP, Limebeer CL, Bedard H, Wood JT (2010) A Novel peripherally restricted cannabinoid receptor antagonist, AM6545, reduces food intake and body weight, but does not cause malaise, in rodents. Br J Pharmacol 161(3):629-642. https://doi.org/10.1111/j.1476-53 81.2010.00908.x

15. Tesch GH, Allen TJ (2007) Rodent models of Streptozotocin-induced diabetic nephropathy. Nephrology (Carlton) 12(3):261-266. https://doi.org/1 0.1111/j.1440-1797.2007.00796.x

16. Ma G, Allen TJ, Cooper ME, Cao Z (2004) Calcium channel blockers amlodipine or mibefradil, ameliorate renal injury in experimental diabetes. Kidney Int 66(3):1090-1098. https://doi.org/10.1111/j.1523-1755.2004.00859.x

17. Edwards CA, O'Brien WD Jr (1980) Modified assay for determination of hydroxyproline in a tissue hydrolyzate. Clin Chim Acta 104(2):161-167. https://doi.org/10.1016/0009-8981(80)90192-8

18. Kang MJ, Ingram A, Ly H, Thai K, Scholey JW (2000) Effects of diabetes and hypertension on glomerular transforming growth factor- $\beta$ receptor expression. Kidney Int 58(4):1677-1685. https://doi.org/10.1046/j.1523-1755.2 000.00328.x

19. Barutta F, Bruno G, Mastrocola R, Bellini S, Gruden G (2018) The role of cannabinoid signaling in acute and chronic kidney diseases. Kidney Int 94(2):252-258. https://doi.org/10.1016/j.kint.2018.01.024
20. Hsu YC, Lei CC, Shih YH, Lin CL, Hsu YC, Lei CC, Shih YH, Lin CL, Lin CL, Lin CL, Hsu YC, Lei CC, Shih YH, Lin CL, Ho C (2015) Induction of Proteinuria by cannabinoid receptors 1 signalling activation in CB1 transgenic mice. Am J Med Sci 349(2):162-168. https://doi.org/10.1097/MAJ.0000000000000352

21. Barutta F, Grimaldi S, Gambino R, Vemuri K, Makriyannis A, Annaratone L, Marzo VD, Bruno G, Gruden G (2017) Dual therapy targeting endocannabinoid system prevents experimental diabetic nephropathy. Nephrol Dial Transplant 32(10):1655-1665. https://doi.org/10.1093/ndt/gfx010

22. Zoja C, Locatelli M, Corna D et al (2016) Therapy with a cannabinoid receptor type 2 agonist limits albuminuria and renal injury in mice with type 2 diabetic nephropathy. 132:59-69

23. Hinden L, Udi S, Drori A et al (2008) Modulation of renal GLUT-2 by the cannabinoid-1 receptor: Implications for the treatment of diabetic nephropathy. J Am Soc Nephrol 29:434-448

24. Williams ME (2005) Diabetic nephropathy: the proteinuria hypothesis. Am J Nephrol 25(2):77-94

25. Drummond K, Mauer M (2002) The early natural history of nephropathy in type 1 diabetes: II. Early renalx structural changes in type 1 diabetes. Diabetes. 51:1580-7

26. Vestra MD, Masiero A, Roiter AM, Saller A, Crepaldi G, Fioretto P et al (2003) Is podocyte injury relevant in diabetic nephropathy? Diabetes 52(4):10311035

27. Wolf G, Ziyadeh FN (2007) Cellular and molecular mechanisms of proteinuria in diabetic nephropathy. Nephron Physiol 106:26-31

28. Ziyadeh FN, Wolf G (2008) Pathogenesis of the podocytopathy and proteinuria in diabetic glomerulopathy. Curr Diabetes Rev 4:39-45

29. Rodby RA, Rohde RD, Sharon Z, Pohl MA, Bain RP, Lewis EJ (1995) The urine protein to creatinine ratio as a predictor of 24-hour urine protein excretion in type 1 diabetic patients with nephropathy. The Collaborative Study Group. Am J Kidney Dis 26:904-909

30. Forbes JM, Cooper ME (2013) Mechanisms of diabetic complications. Physiol Rev 93:137-188

31. Wada J, Makino H (2013) Inflammation and the pathogenesis of diabetic nephropathy. Clin Sci (Lond) 124:139-152

32. Jourdan T, Szanda G, Rosenberg A, Tam J, Earley B, Godlewski G et al (2014) Overactive cannabinoid 1 receptor in podocytes drives type-2 diabetic nephropathy. Proc Natl Acad Aci USA 111:E5420-E5428

33. Barutta F, Bruno G, Grimaldi S, Gruden G (2015) Inflammation in diabetic nephropathy: moving toward clinical biomarkers and targets for treatments. Endocrine 48(3):730-742

34. Radeke HH, Meier B, Topley N, Flo'ge J, Habermehl GG, Resch K (1990) Interleukin 1-alpha and tumor necrosis factor-alpha induce oxygen radical production mesangial cells. Kidney Int 37:767-775

35. Koike N, Takamura T, Kaneko S (2007) Induction of reactive oxygen species from isolated rat glomeruli by protein kinase $C$ activation and TNF-a stimulation, and effects of a phosphodiesterase inhibitor. Life Sci 80:17211728

36. Hruby Z, Beck KF (1997) Cytotoxic effect of autocrine and macrophage derived nitric oxide on cultured rat mesangial cells. Clin Exp Immunol 107: 76-82

37. Pawluczyk IZ, Harris KP (1998) Cytokine interactions promote synergistic fibronectin accumulation by mesangial cells. Kidney Int 54:62-70

38. Comper WD, Russo LM (2008) Where does albuminuria come from in diabetic kidney disease? Curr Diab Rep 8(6):477-485

39. Lee EY, Chung CH, Khoury CC, Yeo TK, Pyagay PE, Wang A et al (2009) The monocyte chemoattractant protein-1/CCR2 loop, inducible by TGF-beta, increases podocyte motility and albumin permeability. Am J Physiol Renal Physiol 297:F85-F94.

40. Barutta F, Corbelli A, Mastrocola R, Gambino R, Di Marzo V, Pinach S et al (2010) Cannabinoid receptor 1 blockade ameliorates albuminuria in experimental diabetic nephropathy. Diabetes 59:1046-1054

41. Nam DH, Lee MH, Kim JE, Song HK, Kang YS, Lee JE et al (2012) blockade of cannabinoid receptor 1 improves insulin resistance, lipid metabolism, and diabetic nephropathy in db/db mice. Endocrinology 153(3):1387-1396

42. Tahara A, Tsukada J, Tomura Y, Yatsu T, Shibaski M et al (2012) Effects of high glucose on AVP-induced hyperplasia, hypertrophy, and type IV collagen synthesis in cultured rat mesangial cells. Endocr Res 37(4):216-227

\section{Publisher's Note}

Springer Nature remains neutral with regard to jurisdictional claims in published maps and institutional affiliations. 